\title{
A comparison of clinical pathologic characteristics between alpha-fetoprotein negative and positive liver cancer patients from Eastern and Southern China
}

\section{Xiaowei Chi}

The Affiliated Hospital of Shandong University of Traditional Chinese Medicine

\section{Liejun Jiang}

The People's Hospital of Guangxi Zhuang Autonomous Region

\section{Yulin Yuan}

The People's Hospital of Guangxi Zhuang Autonomous Region

\section{Xinyan Huang}

The People's Hospital of Guangxi Zhuang Autonomous Region

\section{Xuemei Yang}

The People's Hospital of Guangxi Zhuang Autonomous Region

\section{Steven Hochwald}

Roswell Park Cancer Institute

Jie Liu

Jinan Central Hospital

Huayi Huang ( $\nabla$ Henry.Huang@Mindray.com )

Roswell Park Cancer Institute

\section{Research Article}

Keywords: Alpha-fetoprotein (AFP), hepatocellular carcinoma (HCC), liver cirrhosis, chronic hepatitis B, protein induced vitamin K absence or antagonist-II (PIVKA-II), hepatitis B virus DNA (HBV DNA), carcinoembryonic antigen (CEA), neutrophil to lymphocyte ratio (NLR)

Posted Date: November 8th, 2021

DOI: https://doi.org/10.21203/rs.3.rs-1030390/v1

License: (c) (i) This work is licensed under a Creative Commons Attribution 4.0 International License. Read Full License 


\section{Abstract \\ Background}

Alpha-fetoprotein (AFP) is a biomarker used in clinical management of hepatocellular carcinoma (HCC), however, approximately $40 \%$ of HCC patients do not present with elevated serum AFP levels. This study aimed to investigate the clinical and pathologic characteristics between AFP positive and negative primary liver cancer (PLC) patients to allow for improved clinical management and prognostication of the disease.

\section{Methods}

This study observed a cohort of PLC patients from Eastern and Southern China with comparisons of the clinical and pathologic features between serum AFP positive and negative patient groups; patients with decompensated hepatic cirrhosis, those with chronic hepatitis $B$, and hepatitis B virus (HBV) asymptomatic carrier patients were used as controls. Data included the laboratory results, pathology diagnosis, clinical staging and scores were obtained from routine clinical diagnostic methods.

\section{Results}

Patients with HCC, larger tumor sizes, liver cancer with hepatic cirrhosis, portal vein thrombosis, metastasis, high Child-Pugh score, high Barcelona-Clínic Liver Cancer (BCLC) stage, and advanced clinical stage had significantly higher serum AFP levels. Also, patients with HBsAg and HBeAg positive, high HBV DNA levels had significantly higher serum AFP levels. Patients with high serum AFP levels had higher protein induced by vitamin $\mathrm{K}$ absence or antagonist-II (PIVKA-II), alanine aminotransferase (ALT), aspartate aminotransferase (AST), alpha-l-fucosidase (AFU), gamma-glutamyl transpeptidase ( $\left.\mathrm{Y}^{-\mathrm{GT}}\right)$, $\mathrm{Y}^{-}$ GT /ALT, direct bilirubin (DBIL), indirect bilirubin (IDBIL), fibrinogen, and D-dimer levels. Serum AFP status was inversely associated with serum carcinoembryonic antigen (CEA). Patients with AFP positive had higher white blood cells (WBC), neutrophil, monocyte, and platelet count and neutrophil to lymphocyte ratio (NLR).

\section{Conclusions}

The are significant differences in clinical pathologic characteristics between AFP positive and negative PLC patients which may be helpful for the management and prognostication of the disease.

\section{Introduction}

Primary liver cancer (PLC) is a common malignancy in Asia [1]. About 364,800 new cases of liver cancer were diagnosed in China, resulting in about 318,800 deaths in 2014 [2]. The incidence of liver cancer in 
China is mainly related to hepatitis B virus infection, hepatic fibrosis, and biliary cirrhosis. Treatments for liver cancer include surgical resection, interventional embolization, radiofrequency ablation, liver transplantation, and chemotherapy. However, the postoperative recurrence and metastases rates remain high and the 5 years survival rate is still very low $[3,4]$. The bottle neck for long-term survival improvement is the inability for the diagnosis of early stages of the disease when the tumor size is under $3 \mathrm{~cm}$. Liver cancer screening in high-risk populations relies on serum tumor markers and ultrasonography. For serum biomarkers, the alpha-fetoprotein (AFP) is commonly used as a first line screening tool recommended by guidelines worldwide and is in clinical practice because of easy accessibility, noninvasive nature, and low cost. Serum AFP concentrations $>400 \mathrm{ng} / \mathrm{ml}$ is considered as reliable for supporting the diagnosis of hepatocellular carcinoma. However, about $30-40 \%$ of liver cancers are AFPnegative $(<20 \mathrm{ng} / \mathrm{mL})[5,6]$. The mechanism of AFP repression is unknown, it is hypothesized that silencing of AFP promotors because of mutation or promoter inhibition is one of the reasons [7-9]. Liver cancer patients with AFP negative or weak positive serum tests are usually consistent with the characteristics of high differentiated cancers. Although a negative serum AFP may be associated with favorable liver cancer outcomes, it results in a miss diagnosis of liver cancer in general $[10,11]$. Efforts focusing on identifying new liver cancer serum biomarkers for risk evaluation, early diagnosis, recurrence, and prognosis prediction have been extensively studied, however, no new biomarkers are satisfactory thus far [12-16]. A study found that high neutrophil-lymphocyte ratio (NLR) was associated with low AFP expression in patients with hepatitis B virus (HBV) related HCC, therefore, NLR could be a potential clinical marker of the pathogenesis of AFP negative liver cancer [17]. Another study found that fibrinogen to prealbumin ratio was gradually increased alongside with the development of AFP-negative liver cancer and positively correlated with tumor size and Barcelona Clinic Liver Cancer stages (BCLC) [18]. Thus, we hypothesize that serum biomarkers would vary between AFP-positive and negative liver cancer patients and could be indicators of liver cancer pathogenesis and possibly useful in clinical management and prognostication. In this study, we analyzed the laboratory parameters and clinical characteristics between AFP-positive and negative liver cancer patients from Eastern and Southern China to better understand the pathogenesis of the disease, improving the management, and prognostication.

\section{Patients And Methods}

\section{Patients}

This study retrospectively analyzed a total of 1047 primary liver cancer patients from both Eastern and Southern China including 992 with hepatocellular carcinoma (HCC, 861 males, 131 females, ages from 23 to 89 years and 20 to 83 years, respectively); 53 with cholangiocarcinoma (CCA, 44 males and 9 females, ages from 29 to 78 years and 41 to 72 years, respectively); 2 with hepatocellularcholangiocarcinoma (H-ChC, 1 male and 1 female, age 42 and 63 years, respectively) from 2016 to 2020. The diagnosis of liver cancer followed the 2019 Chinese clinical guidelines for the management of hepatocellular carcinoma: updates and insights $[19,20]$. All liver cancer patients met pretreatment requirement, patients transferred from other hospitals were also excluded. In addition, 121 patients with decompensated hepatic cirrhosis (DHC, 85 males, 36 females, ages from 30 to 86 years and 40 to 85 
years, respectively), 114 with chronic hepatitis $B$ (CHB, 80 males, 34 females, ages from 14 to 72 years and 21 to 68 years, respectively), and 127 with hepatitis B virus asymptomatic carriers (AsC, 68 males, 59 females, ages from 5 to 67 years and 25 to 80 years, respectively) were used as control groups. Diagnosis of DHC followed the EASL Clinical Practice Guidelines for the management of patients with decompensated cirrhosis [21], and diagnosis of CHB virus infection followed the EASL Clinical Practice Guidelines: Management of chronic hepatitis B virus infection and AASLD 2018 hepatitis B guidance $[22,23]$. This study was approved by the Institute Review Board (Ethics Committee) of The Affiliated Hospital of Shandong University of Traditional Chinese Medicine and The People's Hospital of Guangxi Zhuang Autonomous Region for the collection of patients' information. Patients' demographics are listed in Supplementary Table S1.

\section{Chemiluminescence immunoassay of serum biomarkers}

Serum AFP, carcinoembryonic antigen (CEA), cancer antigen 125 (CA125), and cancer antigen 199 were analyzed on the Cobas e801 platform (Roche, Rotkreuz, Switzerland) and UniCel Dxl 800 Access (Beckman Coulter, Brea, California, USA); Protein induced by vitamin K absence or antagonist-II (PIVKA-II) was analyzed on the ARCHITECT i2000SR platform (Abbott Park, Illinois, USA); HBsAg and HBeAg were analyzed on the EasyCuta platform (PerkinElmer, Taicang, Suzhou, China) following the manufacturers' instruction and laboratory standard operating procedures. Serum AFP level lower than $20 \mathrm{ng} / \mathrm{mL}$ was defined as AFP negative, while it was defined as AFP positive if the concentration was higher than 20 $\mathrm{ng} / \mathrm{mL}$.

\section{Clinical chemistry analysis}

Serum homocysteine (Hcy), ferritin (SF), alanine transaminase (ALT), g-glutamyl transpeptidase (g-GT), aspartate aminotransferase (AST), alpha-L-fucosidase (AFU), direct bilirubin (DBIL), indirect bilirubin (IBIL), total protein (TP), and albumin (ALB) were analyzed on the AU5800 platform (Beckman Coulter, Brea, California, USA) following the manufacturer's instruction and laboratory standard operating procedures.

\section{Hematology analysis}

Hematology analysis of blood cells (complete blood count and differentiation) were performed on the XN 9000 hematology analyzer (Sysmex, Kobe, Japan) and BC 6900 hematology analyzer (Mindray, Shenzhen, China) following the manufacturers' instruction and laboratory standard operating procedures.

\section{Coagulation analysis}

Prothrombin time (PT), fibrinogen, and D-dimer were analyzed using the STA-R Evolution (Diagnostica Stago S.A.S., Asnières sur Seine Cedex, France) following the manufacturer's instruction and laboratory standard operating procedures. The international normalized ratio (INR) was automatically calculated by the analyzer. 


\section{Hepatitis B virus DNA detection}

Hepatitis B virus (HBV) DNA was detected on the C1000 Touch Thermocycler (Bio-Rad, Hercules, California, USA) by using the real time polymerase chain reaction (PCR) technique following the manufacturer's instruction and laboratory standard operating procedures. The cut-off value for DNA levels for analysis was set at $500 \mathrm{IU} / \mathrm{mL}$.

\section{Pathology diagnosis}

The tumor histologic types and differentiation were characterized by pathology examination of routine pathologic diagnosis from surgical tissues.

\section{Child-Pugh scoring and BCLC staging classification of hepatocellular carcinoma}

The Child-Pugh Scoring was performed according to the scoring system [24]. The BCLC staging classification of hepatocellular carcinoma was used in routine clinical management [25].

\section{Statistical analysis}

All data was analyzed using the SPSS version 26 and GraphPad Prism version 9 software. Since the data sets were skewed, thus, nonparametric tests (Mann-Whitney U Test, Kruskai-Wallis H Test, Spearman Test, and Pairwise comparison) were used for the analysis. A $p$ value $<0.05$ was considered significant.

\section{Results}

\section{Normality test result of data set}

The statistical analysis indicated that the data was skewed. The distribution of serum AFP in patient groups is shown in Supplementary Figure S1. Most patients' AFP levels were at the lower end (left in the histogram of Fig. S1).

\section{Comparison of serum AFP levels among patient groups}

Table 1 lists the comparison of serum AFP levels among patient groups using the nonparametric method. Statistical results of pairwise comparison are shown in Supplementary Figure S2 A. The results show that serum AFP levels in HCC and CCA patients are significantly higher than in AsC patients $(p<0.0001$ for both), AFP levels in HCC patients are significantly higher than in CCA, CHB, and DHC patients $(p<0.0001$ for all) (Figure S2 A).

\section{Association between serum AFP levels and clinical pathologic features in liver cancer patients}

Serum AFP levels in patients with tumor size $\geq 10 \mathrm{~cm}$ were significantly higher than that of $<10 \mathrm{~cm}$ $(p=0.000)$; patients with liver cirrhosis had higher AFP levels $(p=0.000)$; AFP levels in HCC patients were significantly higher than that of CCA patients $(p=0.000)$; Patients with portal vein thrombosis had higher 
AFP levels $(p=0.000)$; patients who had metastasis also had higher AFP levels $(p=0.000)$; AFP levels in patients with large tumors were significantly higher than those with diffuse and single nodule tumors $(p=0.000)$; high Child-Pugh score patients had higher AFP levels than those with low scores $(p=0.000)$; patients with high BCLC stage had higher AFP levels than those with low stages $(p=0.000)$; similarly, patients with more advanced clinical stages had higher AFP levels than that of lower stages $(p=0.000)$. There was no significant correlation between tumor differentiation and serum AFP levels $(p=0.069)$. Table 2. Supplementary Figure S2 B-E show the pairwise comparison (only showing the comparison with $p<$ 0.05).

\section{Association between serum AFP status and hepatitis B biomarkers in liver cancer patients}

Patients with HBsAg and HBeAg positive and HBV DNA amount $>500 \mathrm{IU} / \mathrm{mL}$ had significantly higher serum AFP levels ( $p=0.000$ for all). Table 3 .

\section{Association between serum AFP status and other tumor markers in liver cancer patients}

Patients with high serum AFP levels had higher serum PIVKA-II $(p=0.000)$. There was a negative correlation between serum AFP and CEA levels $(p=0.031)$. There is no significant correlation between serum AFP and CA-125 and CA-199 levels ( $\mathrm{p}=0.474$ and 0.183, respectively). Supplementary Table S2. The Overlay Scatter of serum AFP levels with PIVKA-II, CEA, CA-125, and CA-199 are shown in Figure 1.

\section{Association between serum AFP status and liver function biomarkers in liver cancer patients}

Patients with high serum AFP levels had higher serum alanine aminotransferase (ALT), g-glutamyl transpeptidase (g-GT), aspartate aminotransferase (AST), alpha-L-fucosidase (AFU) activities $(p=0.000$ for all), and higher $g-G T / A L T$ ratio $(p=0.007)$. Patients with high serum AFP levels also had higher serum direct bilirubin (DBIL) and indirect bilirubin (IBIL) levels $(p=0.000$ and $p=0.025$, respectively) and fibrinogen $(p=0.008)$ as well as $D$-Dimer $(p=0.000)$. There was no significant correlation between serum AFP levels and serum homocysteine (Hcy, $p=0.445)$, ferritin $(S F, p=0.828)$, total protein $(T P, p=0.166)$, and albumin (ALB, $p=0.336)$. The prothrombin time did not show significant different either $(p=0.070)$ between AFP negative and positive patients. Table 4.

\section{Association between serum AFP status and hematology parameters in liver cancer patients}

Table 5 shows that serum AFP status is positively associated with white blood cell (WBC) count, neutrophils, monocytes, and platelets ( $p=0.006,0.001,0.035$, and 0.012 , respectively). Serum AFP positive patients have lower lymphocytes than negative patients $(p=0.001)$, thus, the neutrophils to lymphocytes ration (NLR) is higher in serum AFP positive patients $(p=0.001)$.

\section{Discussion}

AFP is a major plasma protein produced by the yolk sac and the liver during fetal 
life. AFP expression in adults is often associated with hepatoma or teratoma [26].

The underlying mechanism of AFP expression status in liver cancer and its role in the development and prognosis is still unclear; promoter polymorphism or silencing of AFP gene is believed to be the major reason $[27,28]$. Understanding the clinical pathologic characteristics of liver cancer patients with low and high serum AFP could be helpful for clinical management and prognostication of this deadly disease.

\section{Serum AFP status was associated with tumor types}

In this observation, we found that serum AFP levels in HCC patients were significantly higher than in cholangiocarcinoma. Serum AFP is a marker for HCC, and AFP levels tend to be lower in cholangiocarcinoma than in HCC [29]. Our observation was consistent with previous reports.

\section{High serum AFP level was associated with unfavorable prognostic factors}

We also found that patients with larger tumors, liver cancers with hepatic cirrhosis, portal vein thrombosis, metastasis, and massive hepatocellular carcinomas had higher serum AFP levels. These suggest that patients with higher serum AFP levels tend to have poor clinical outcome [30-33]. It is also possible that higher burden of disease exists in these patients accounting for the increased AFP levels.

\section{Association of serum AFP levels between Child-Pugh score, BCLC stage, and clinical stage}

Serum AFP levels were significantly higher in patients with high Child-Pugh score, high BCLC stage, and advanced clinical stage. Lim et al reported that AFP levels and Child-Pugh scores were associated with brain metastasis in HCC patients [34]. Liu et al reported that based on BCLC staging, serum AFP response was correlated with the efficacy of transarterial chemoembolization in HCC patients [35]. Incorporation of serum AFP into the BCLC staging system was helpful in predicting the outcome of HCC patients, and AFP positive was an independent poor prognostic factor [36]. Gomaa et al found that the addition of AFP and ascites to the BCLC staging system improved the prognostic prediction for early and intermediate stages of liver cancer patients [37].

\section{Patients with HBsAg and HBeAg positive, and high HBV DNA levels had significantly higher serum AFP levels}

Again, our observation further confirmed that serum AFP levels were associated with hepatitis B viral biomarkers positivity as reported previously [38]. Liver cancer patients with positive $\mathrm{HBsAg}$ and $\mathrm{HBeAg}$, high levels of HBV DNA had higher serum AFP levels. This further indicates that active viral replication and chronic liver disorder and hepatocyte damage is occurring in liver cancer patients $[39,40]$.

\section{Association between serum AFP levels and other tumor markers}

Patients with high serum AFP levels also had higher serum PIVKA-II. PIVKA-II is usually used in addition to AFP measurement for HCC diagnosis [41]. However, in this study, we found that there was a positive association between serum AFP and PIVKA-II levels in liver cancer patients. Si et al reported that 
combined analyses of serum AFP and PIVKA-II increased the diagnostic performance for HBV-related HCC [42]. Surprisingly, we found that serum AFP levels were inversely associated with serum CEA levels $(p=0.031)$ as seen in Supplementary Table S2 and Figure 1. Report mentioned that elevated serum AFP and CEA were found in advanced hepatocellular carcinoma with extrahepatic metastasis [43]. Gou et al found that both serum CEA and CA-199 increased but not AFP in primary adenosquamous carcinoma of the liver [44]. Serum CEA level may differ according to HCC subgroups which needs to be further investigated [45].

\section{Association between serum AFP status and liver function, hemostatic status in liver cancer patients}

As described above, serum AFP status was associated with Child-Pugh score. We further analyzed individual elements of the Child-Pugh scoring system, the ALT, AST, AFU, g-GT, g-GT/ALT ratio, DBIL, IBIL levels, fibrinogen, and D-dimer levels with serum AFP status. Results showed that patients with high serum AFP levels had higher serum ALT, AST, AFU, g-GT, g-GT/ALT ratio, DBIL, and IBIL levels, as well as fibrinogen and D-dimer levels. These results further confirmed the clinical usage of Child-Pugh scoring system for liver cancers. Elevated fibrinogen and D-dimer levels may suggest a potential deep venous thrombosis, or other complications in advanced tumors including liver cancer.

\section{Association of serum AFP status with hematology parameters}

Our observation found that serum AFP status was positively associated with peripheral blood WBC, neutrophils, monocytes, platelets, and the neutrophils to lymphocytes ratio (NLR). These parameters may suggest that an inflammatory or infection condition occurred in patients with high serum AFP levels, since the AFP status was associated with unfavorable clinical pathologic features as described above. Shiraki et al reported that elevated NLR is predictive of a poor survival in patients with primary HCC showing normal AFP levels [46]. Another report on a systemic review of the literature showed that NLR and albumin in HCC predicted survival better than the conventional AFP [47]. Our finding on NLR was opposite to that of Huang et al [18].

\section{Conclusions}

In summary, the results especially the laboratory parameters observed in our study in AFP negative liver cancer patients could be used for diagnosis and prognostic evaluation of these patients. HBV DNA viral load and hematologic indices are especially new parameters in associating with serum AFP status in liver cancers.

\section{Abbreviations}

$\mathrm{HCC}$, hepatocellular carcinoma; PLC, primary liver cancer; CCA, cholangiocarcinoma; H-ChC, hepatocellular-cholangiocarcinoma; DHC, decompensated hepatic cirrhosis; CHB, chronic hepatitis B; AsC, hepatitis B virus asymptomatic carrier; PVT, portal vein thrombosis; $\mathrm{MHC}$, massive hepatocellular carcinoma; BCLC, Barcelona clinic liver cancer staging; CEA, carcinoembryonic antigen; PIVKA-ll, protein 
induced by vitamin $\mathrm{K}$ absence or antagonist-II; CA-125, cancer antigen 125; CA-199, cancer antigen 199; Hcy, homocysteine; SF, serum ferritin; ALT, alanine aminotransferase; $ү g-G T$, $ү g$-glutamyl transpeptidase; AST, Aspartate aminotransferase; AFU, alpha-L-fucosidase; DBIL, direct bilirubin; IBIL, indirect bilirubin; TP, total protein; ALB, albumin; PT, prothrombin time; INR, international normalized ratio; WBC, white blood cell count; Neu, neutrophil count; Neu\%, percentage of neutrophils; Lym, lymphocyte count; Lym\%, percentage of lymphocytes; NLR, neutrophil to lymphocyte ratio; Mon, monocyte count; Mon\%, percentage of monocytes.

\section{Declarations}

\section{Acknowledgements}

The authors would like to thank The People's Hospital of Guangxi Zhuang Autonomous Region and The Affiliated Hospital of Shandong University of Traditional Chinese Medicine for supporting on this study.

\section{Authors' contributions}

Xiaowei Chi: collected clinical and pathologic data; Liejun Jiang: collected data and data analysis; Yulin Yuan: collected data; Xinyan Huang: collected data; Xuemei Yang: collected data; Steven Hochwald: discussion and clinical instruction; Jie Liu: project organization; Huayi Huang: conceived the study and writing.

\section{Funding}

No specific funding was disclosed.

\section{Availability of data and materials}

Data is available by contacting Huayi Huang at Henry.Huang@Mindray.com.

\section{Declarations}

\section{Ethics approval and consent to participate}

This study was approved by the Institute Review Board (Ethics Committee) of The Affiliated Hospital of Shandong University of Traditional Chinese Medicine and The People's Hospital of Guangxi Zhuang Autonomous Region for the collection of patients' information. The study was waived by the ethics committee/institutional review board of The Affiliated Hospital of Shandong University of Traditional Chinese Medicine (approval No. 2021 (025)) and The People's Hospital of Guangxi Zhuang Autonomous Region (approval No. KY-LW-2021-6) for an informed consent because the data collection was conducted retrospectively.

All methods used in this study were performed in accordance with the relevant guidelines and regulations in routine clinical practice. 


\section{Consent for publication}

Not applicable.

\section{Competing interests}

No competing interests.

\section{Author details}

1 Department of Laboratory Medicine, The Affiliated Hospital of Shandong University of Traditional Chinese Medicine, 42 Wenhua West Rd, Jinan, Shandong 250012, China.

2 Department of Laboratory Medicine, The People's Hospital of Guangxi Zhuang Autonomous Region, 6 Taoyuan Rd, Nanning, Guangxi 530021, China.

3 Department of Nuclear Medicine, The People's Hospital of Guangxi Zhuang Autonomous Region, 6 Taoyuan Rd, Nanning, Guangxi 530021, China.

4 Department of Surgical Oncology, Roswell Park Comprehensive Cancer Center, Elm and Carton Streets, Buffalo, New York 14263, USA.

5 Department of Laboratory Medicine, Jinan Central Hospital, 105 Jiefang Rd, Jinan, Shandong 250013, China.

6 School of Medical Laboratory, Youjiang Medical University for Nationalities, No. 98 Chengxiang Road, Baise, Guangxi 533000, China.

7 Mindray North America, 800 MacArthur Boulevard, Mahwah, NJ 07430, USA.

\section{References}

1. https://www.iarc.who.int/featured-news/new-world-cancer-report/

2. Zheng R, Qu C, Zhang S, Zeng H, Sun K, Gu X, Xia C, Yang Z, Li H, Wei W, Chen W, He J. Liver cancer incidence and mortality in China: Temporal trends and projections to 2030. Chin J Cancer Res. 2018;30(6):571-9.

3. Sarveazad A, Agah S, Babahajian A, Amini N, Bahardoust M. Predictors of 5 year survival rate in hepatocellular carcinoma patients. J Res Med Sci. 2019;24:86.

4. Wang XH, Long LH, Cui Y, Jia AY, Zhu XG, Wang HZ, Wang Z, Zhan CM, Wang ZH, Wang WH. MRIbased radiomics model for preoperative prediction of 5-year survival in patients with hepatocellular carcinoma. Br J Cancer. 2020;122(7):978-85.

5. Enguita-Germán M, Fortes P. Targeting the insulin-like growth factor pathway in hepatocellular carcinoma. World J Hepatol. 2014;6(10):716-37. 
6. Guo W, Sun YF, Shen MN, Ma XL, Wu J, Zhang CY, Zhou Y, Xu Y, Hu B, Zhang M, Wang G, Chen WQ, Guo L, Lu RQ, Zhou CH, Zhang X, Shi YH, Qiu SJ, Pan BS, Cao Y, Zhou J, Yang XR, Fan J. Circulating Tumor Cells with Stem-Like Phenotypes for Diagnosis, Prognosis, and Therapeutic Response Evaluation in Hepatocellular Carcinoma. Clin Cancer Res. 2018;24(9):2203-13.

7. Li XJ, Shao DH, He ML, Liang GW. Association of Common Variants in HNF1A Gene with Serum AFP Level in Healthy Chinese Individuals and HCC Patients. Dis Markers. 2019;2019:6273497.

8. Shen S, Feng H, Liu L, Su W, Yu L, Wu J. TCP10L negatively regulates alpha-fetoprotein expression in hepatocellular carcinoma. BMB Rep. 2020;53(8):431-6.

9. Zhang L, Wang K, Deng Q, Li W, Zhang X, Liu X. Identification of Key Hydroxymethylated Genes and Transcription Factors Associated with Alpha-Fetoprotein-Negative Hepatocellular Carcinoma. DNA Cell Biol. 2019;38(11):1346-56.

10. Wang X, Wang Q. Alpha-Fetoprotein and Hepatocellular Carcinoma Immunity. Can J Gastroenterol Hepatol. 2018;2018:9049252.

11. Carr BI, Akkiz H, Üsküdar O, Yalçın K, Guerra V, Kuran S, Karaoğullarından Ü, Altıntaş E, Özakyol A, Tokmak S, Ballı T, Yücesoy M, Bahçeci Hi, Ülkü A, Akçam T, Polat KY, Ekinci N, Şimşek H, Örmeci N, Sonsuz A, Demir M, Kılıç M, Uygun A, Demir A, Delik A, Arslan B, Doran F, Yilmaz S, Tokat Y. HCC with low- and normal-serum alpha-fetoprotein levels. Clin Pract (Lond). 2018;15(1):453-64.

12. Wang K, Li M, Qin J, Sun G, Dai L, Wang P, Ye H, Shi J, Cheng L, Yang Q, Qiu C, Jiang D, Wang X, Zhang J. Serological Biomarkers for Early Detection of Hepatocellular Carcinoma: A Focus on Autoantibodies against Tumor-Associated Antigens Encoded by Cancer Driver Genes. Cancers (Basel). 2020;12(5):1271.

13. Chen H, Zhang Y, Li S, Li N, Chen Y, Zhang B, Qu C, Ding H, Huang J, Dai M. Direct comparison of five serum biomarkers in early diagnosis of hepatocellular carcinoma. Cancer Manag Res. 2018;10:1947-58.

14. Zhang X, Wang T, Zhang KH, Chen SH, He YT, Wang YQ. Simple Clinical Metrics Enhance AFP to Effectively Identify Cirrhotic Patients With Complicating Hepatocellular Carcinoma at Various AFP Levels. Front Oncol. 2020;9:1478.

15. Wang T, Zhang KH. New Blood Biomarkers for the Diagnosis of AFP-Negative Hepatocellular Carcinoma. Front Oncol. 2020;10:1316.

16. Wang X, Mao M, He Z, Zhang L, Li H, Lin J, He Y, Dai S, Hu W, Liu W. Development and Validation of a Prognostic Nomogram in AFP-negative hepatocellular carcinoma. Int J Biol Sci. 2019;15(1):221-8.

17. Wang H, Xiang Y, Li X, Liu S, Liu L. High lymphocyte-to-monocyte ratio is associated with low afetoprotein expression in patients with hepatitis B virus-associated hepatocellular carcinoma. Mol Med Rep. 2020;22(4):2673-84.

18. Huang L, Mo Z, Hu Z, Zhang L, Qin S, Qin X, Li S. Diagnostic value of fibrinogen to prealbumin ratio and gamma-glutamyl transpeptidase to platelet ratio in the progression of AFP-negative hepatocellular carcinoma. Cancer Cell Int. 2020;20:77. 
19. Xie DY, Ren ZG, Zhou J, Fan J, Gao Q. 2019 Chinese clinical guidelines for the management of hepatocellular carcinoma: updates and insights. Hepatobiliary Surg Nutr. 2020;9(4):452-63.

20. http://guide.medlive.cn/

21. European Association for the Study of the Liver. EASL Clinical Practice Guidelines for the management of patients with decompensated cirrhosis. J Hepatol. 2018;69:406-60.

22. European Association for the Study of the Liver. EASL 2017 Clinical Practice Guidelines on the management of hepatitis B virus infection. J Hepatol. 2017;67:370-98.

23. Terrault NA, Lok ASF, McMahon BJ, Chang KM, Hwang JP, Jonas MM, Brown RS Jr, Bzowej NH, Wong JB. Update on prevention, diagnosis, and treatment of chronic hepatitis B: AASLD 2018 hepatitis B guidance. Hepatology. 2018;67(4):1560-99.

24. Tsoris A, Marlar CA. Use of The Child Pugh Score in Liver Disease. 2021 Mar 22. In: StatPearls [Internet]. Treasure Island (FL): StatPearls Publishing; 2021 Jan-. PMID: 31194448.

25. Pons F, Varela M, Llovet JM. Staging systems in hepatocellular carcinoma. HPB (Oxford). $2005 ; 7: 35-41$.

26. https://genecards.weizmann.ac.il/v3/cgi-bin/carddisp.pl?gene=AFP

27. Chen GG, Ho RL, Wong J, Lee KF, Lai PB. Single nucleotide polymorphism in the promoter region of human alpha-fetoprotein (AFP) gene and its significance in hepatocellular carcinoma (HCC). Eur J Surg Oncol. 2007;33(7):882-6.

28. Suriapranata IM, Sudania WM, Tjong WY, Suciptan AA, Gani RA, Hasan I, Sanityoso A, Budihusodo U, Miskad UA, Akil F, Lelosutan SA, Martamala R, Yusuf I, Lesmana LA, Sulaiman A, Tai S. Alphafetoprotein gene polymorphisms and risk of HCC and cirrhosis. Clin Chim Acta. 2010;411(5-6):3518.

29. Shao S, Liang Y, Kuang S, Chen J, Shan Q, Yang H, Zhang Y, Wang B, J Fowler K, Wang J, B Sirlin C. Diagnostic performance of LI-RADS version 2018 in differentiating hepatocellular carcinoma from other hepatic malignancies in patients with hepatitis B virus infection. Bosn J Basic Med Sci. 2020;20(3):401-10.

30. Balogh J, Victor D 3rd, Asham EH, Burroughs SG, Boktour M, Saharia A, Li X, Ghobrial RM, Monsour HP Jr. Hepatocellular carcinoma: a review. J Hepatocell Carcinoma. 2016;3:41-53.

31. Poddar N, Avezbakiyev B, He Z, Jiang M, Gohari A, Wang JC. Hepatocellular carcinoma presenting as an incidental isolated malignant portal vein thrombosis. J Gastrointest Cancer. 2012;43(3):486-9.

32. Hsu CY, Lee YH, Huang YH, Hsia CY, Su CW, Lin HC, Lee RC, Chiou YY, Lee FY, Huo TI, Lee SD. Ascites in patients with hepatocellular carcinoma: prevalence, associated factors, prognostic impact, and staging strategy. Hepatol Int. 2013;7(1):188-98.

33. Carr BI, Guerra V. Thrombocytosis and hepatocellular carcinoma. Dig Dis Sci. 2013;58(6):1790-6.

34. Lim S, Lee S, Lim JY, Park JS, Seong JS, Chang WS, Han KH, Choi HJ. Hepatocellular carcinoma specific graded prognostic assessment can predict outcomes for patients with brain metastases from hepatocellular carcinoma. J Neurooncol. 2014;120(1):199-207. 
35. Liu G, Ouyang Q, Xia F, Fan G, Yu J, Zhang C, Wang D. Alpha-fetoprotein response following transarterial chemoembolization indicates improved survival for intermediate-stage hepatocellular carcinoma. HPB (Oxford). 2019;21(1):107-13.

36. Zhang N, Gu J, Yin L, Wu J, Du MY, Ding K, Huang T, He X. Incorporation of alpha-fetoprotein(AFP) into subclassification of BCLC C stage hepatocellular carcinoma according to a 5-year survival analysis based on the SEER database. Oncotarget. 2016;7(49):81389-401.

37. Gomaa Al, Al-Khatib A, Abdel-Razek W, Hashim MS, Waked I. Ascites and alpha-fetoprotein improve prognostic performance of Barcelona Clinic Liver Cancer staging. World J Gastroenterol. 2015;21(18):5654-62.

38. Akuta N, Suzuki F, Kobayashi M, Hara T, Sezaki H, Suzuki Y, Hosaka T, Kobayashi M, Saitoh S, Ikeda K, Kumada H. Correlation between hepatitis B virus surface antigen level and alpha-fetoprotein in patients free of hepatocellular carcinoma or severe hepatitis. J Med Virol. 2014;86(1):131-8.

39. Chen DS, Sung JL. Relationship of hepatitis B surface antigen to serum alpha-fetoprotein in nonmalignant diseases of the liver. Cancer. 1979;44(3):984-92.

40. Ding Y, Liu K, Xu Y, Zhao Q, Lou S, Xiang X, Yan L, Cao Z, Xie Q, Zhu C, Bao S, Wang H. Combination of inflammatory score/liver function and AFP improves the diagnostic accuracy of HBV-related hepatocellular carcinoma. Cancer Med. 2020;9(9):3057-69.

41. Feng H, Li B, Li Z, Wei Q, Ren L. PIVKA-II serves as a potential biomarker that complements AFP for the diagnosis of hepatocellular carcinoma. BMC Cancer. 2021;21(1):401.

42. Si YQ, Wang XQ, Fan G, Wang CY, Zheng YW, Song X, Pan CC, Chu FL, Liu ZF, Lu BR, Lu ZM. Value of AFP and PIVKA-II in diagnosis of HBV-related hepatocellular carcinoma and prediction of vascular invasion and tumor differentiation. Infect Agent Cancer. 2020;15(1):70.

43. Hanazawa T, Fukami Y, Osawa T, Kurahashi S, Matsumura T, Saito T, Komatsu S, Kaneko K, Tsuzuki T, Sano T. A case of resected hepatocellular carcinoma with gallbladder metastasis. Surg Case Rep. $2021 ; 7(1): 145$.

44. Gou Q, Fu S, Xie Y, Zhang M, Shen Y. Treatment and Survival Patterns of Primary Adenosquamous Carcinoma of the Liver: A Retrospective Analysis. Front Oncol. 2021;11:621594.

45. Abdelgawad IA. Epithelial Cell Adhesion Molecule mRNA Can be a Potential Marker to Predict Metastasis in Hepatocellular Carcinoma Patients. Asian Pac J Cancer Prev. 2020;21(3):861-6.

46. Shiraki T, Ishizuka M, Kubota K, Kato M, Matsumoto T, Mori S, Shimizu T, Aoki T. An elevated neutrophil-to-lymphocyte ratio predicts a poor postoperative survival in primary hepatocellular carcinoma patients with a normal preoperative serum level of alpha-fetoprotein. Surg Today. 2019;49(8):661-9.

47. Bannaga A, Arasaradnam RP. Neutrophil to lymphocyte ratio and albumin bilirubin grade in hepatocellular carcinoma: A systematic review. World J Gastroenterol. 2020;26(33):5022-49.

\section{Tables}


Table 1 Comparison of serum AFP levels among patient groups

\begin{tabular}{lllllll} 
& $\mathrm{n}$ & Median & P25-P75 & Mean Rank & Test Statistic & $P$ \\
\hline HCC & 992 & 179.4 & $9.25-1210.00$ & 840.51 & 405.518 & 0.000 \\
\hline H-ChC & 2 & 225.18 & & 596.75 & & \\
\hline CCA & 53 & 4.62 & $3.03-187.66$ & 551.54 & & \\
\hline CHB & 114 & 5.72 & $2.80-21.99$ & 473.05 & & \\
\hline DHC & 121 & 4.41 & $2.16-11.53$ & 380.97 & & \\
\hline AsC & 127 & 2.61 & $1.91-3.46$ & 229.19 & &
\end{tabular}

HCC: hepatocellular carcinoma; CCA: cholangiocarcinoma; H-ChC: hepatocellular-cholangiocarcinoma; DHC: decompensated hepatic cirrhosis; $\mathrm{CHB}$ : chronic hepatitis $\mathrm{B}$; AsC: hepatitis B virus asymptomatic carrier.

Table 2 Association between serum AFP levels and clinical pathologic features 


\begin{tabular}{|c|c|c|c|c|c|c|c|}
\hline & & $\mathrm{n}$ & Median & P25-P75 & $\begin{array}{l}\text { Mean } \\
\text { Rank }\end{array}$ & $\begin{array}{l}\text { Test } \\
\text { Statistic }\end{array}$ & $P$ \\
\hline Tumor size ${ }^{a}$ & $<10 \mathrm{~cm}$ & 601 & 76.22 & $\begin{array}{l}6.48- \\
1000.00\end{array}$ & 403.99 & -7.29 & 0.000 \\
\hline $\begin{array}{l}\text { (largest in } \\
\text { diameter) }\end{array}$ & $\geq 10 \mathrm{~cm}$ & 294 & 800.00 & $\begin{array}{l}35.47- \\
3000.00\end{array}$ & 537.96 & & \\
\hline \multirow[t]{2}{*}{ Liver cirrhosis $^{a}$} & No & 423 & 92.20 & $\begin{array}{l}5.02- \\
1000.00\end{array}$ & 484.06 & -3.523 & 0.000 \\
\hline & Yes & 624 & 214.51 & $\begin{array}{l}12.77- \\
1210.00\end{array}$ & 551.08 & & \\
\hline \multirow[t]{2}{*}{$\begin{array}{l}\text { Histologic types } \\
\text { a }\end{array}$} & $\mathrm{HCC}$ & 992 & 177.80 & $\begin{array}{l}9.25- \\
1210.00\end{array}$ & 534.05 & -5.125 & 0.000 \\
\hline & $\mathrm{CCA}$ & 53 & 4.62 & $\begin{array}{l}3.03- \\
187.66\end{array}$ & 316.21 & & \\
\hline \multirow[t]{2}{*}{ PVT ${ }^{a}$} & No & 753 & 85.90 & $\begin{array}{l}6.40- \\
1000.00\end{array}$ & 486.39 & -6.448 & 0.000 \\
\hline & Yes & 294 & 800.00 & $\begin{array}{l}36.19- \\
1794.64\end{array}$ & 620.34 & & \\
\hline \multirow[t]{2}{*}{ Metastasis $^{a}$} & No & 686 & 103.59 & $\begin{array}{l}6.75- \\
1000.00\end{array}$ & 495.38 & -4.226 & 0.000 \\
\hline & Yes & 361 & 415.39 & $\begin{array}{l}15.99- \\
1871.47\end{array}$ & 578.38 & & \\
\hline \multirow[t]{4}{*}{ Types of tumor ${ }^{b}$} & $\begin{array}{l}\text { Single } \\
\text { nodule }\end{array}$ & 386 & 30.85 & $\begin{array}{l}4.81- \\
800.00\end{array}$ & 429.58 & 92.416 & 0.000 \\
\hline & $\begin{array}{l}\text { Multiple } \\
\text { nodules }\end{array}$ & 259 & 154.00 & $\begin{array}{l}8.19- \\
1210.00\end{array}$ & 509.59 & & \\
\hline & Diffuse & 144 & 200.44 & $\begin{array}{l}15.89- \\
1288.44\end{array}$ & 559.82 & & \\
\hline & Large tumor & 258 & 905.02 & $\begin{array}{l}\text { 72.28- } \\
3000.00\end{array}$ & 659.73 & & \\
\hline \multirow[t]{3}{*}{$T^{b}$} & Low & 48 & 74.91 & $\begin{array}{l}7.68- \\
750.92\end{array}$ & 104.66 & 5.348 & 0.069 \\
\hline & Medium & 120 & 23.06 & $\begin{array}{l}4.33- \\
780.26\end{array}$ & 92.46 & & \\
\hline & High & 18 & 6.56 & $3.34-64.84$ & 70.67 & & \\
\hline \multirow[t]{2}{*}{ Child-Pugh ${ }^{b}$} & $A$ & 616 & 69.68 & $\begin{array}{l}6.40- \\
1000.00\end{array}$ & 472.77 & 47.650 & 0.000 \\
\hline & B & 311 & 442.89 & $\begin{array}{l}17.14- \\
2120.40\end{array}$ & 573.48 & & \\
\hline
\end{tabular}




\begin{tabular}{|c|c|c|c|c|c|c|c|}
\hline & C & 118 & 1000.00 & $\begin{array}{l}110.66- \\
1254.27\end{array}$ & 652.20 & & \\
\hline \multirow[t]{5}{*}{ BCLC $^{b}$} & 0 & 22 & 12.65 & 4.34-70.97 & 261.96 & 50.127 & 0.000 \\
\hline & $A$ & 216 & 33.05 & $\begin{array}{l}4.56- \\
511.96\end{array}$ & 315.02 & & \\
\hline & B & 226 & 310.60 & $\begin{array}{l}\text { 15.97- } \\
1866.01\end{array}$ & 417.45 & & \\
\hline & C & 283 & 290.89 & $\begin{array}{l}\text { 14.37- } \\
1210.00\end{array}$ & 429.75 & & \\
\hline & $\mathrm{D}$ & 36 & 1000.00 & $\begin{array}{l}114.29- \\
3000.00\end{array}$ & 496.32 & & \\
\hline \multirow[t]{4}{*}{ Clinical staging ${ }^{b}$} & I & 63 & 6.99 & $\begin{array}{l}3.39- \\
159.21\end{array}$ & 111.44 & 30.016 & 0.000 \\
\hline & II & 39 & 213.21 & $\begin{array}{l}7.31- \\
886.00\end{array}$ & 164.81 & & \\
\hline & III & 121 & 114.35 & $\begin{array}{l}6.52- \\
1182.25\end{array}$ & 155.85 & & \\
\hline & IV & 94 & 887.495 & $\begin{array}{l}21.57- \\
1210.00\end{array}$ & 192.52 & & \\
\hline
\end{tabular}

a: Mann-Whitney U; b: Kruskai-Wallis H; PVT: Thrombosis of portal vein; Metastasis: lymph nodes or distant organ metastasis; TD: tumor differentiation; BCLC: Barcelona clinic liver cancer staging

Table 3 Association between serum AFP levels and hepatitis B biomarkers in liver cancer patients (MannWhitney)

\begin{tabular}{llllllll} 
& & $\mathrm{n}$ & Median & P25-P75 & Mean Rank & $\mathrm{Z}$ & $P$ \\
\hline HBsAg & negative & 211 & 8.62 & $3.14-800.00$ & 372.36 & -7.752 & 0.000 \\
\hline positive & 814 & 226.91 & $15.18-1210.00$ & 549.46 & & \\
\hline HBeAg & negative & 899 & 141.41 & $6.99-1123.83$ & 501.22 & -3.915 & 0.000 \\
\hline & positive & 130 & 401.51 & $34.49-3000.00$ & 610.27 & & \\
\hline HBV DNA & $\leq 500$ & 398 & 108.03 & $6.8-1000.00$ & 355.24 & -5.107 & 0.000 \\
\hline 囚IU/mLX & $>500$ & 394 & 515.72 & $29.45-1859.49$ & 438.18 & &
\end{tabular}


Table 4 Association between serum AFP levels and liver function markers in patients with AFP negative and AFP positive (Mann-Whitney) 


\begin{tabular}{|c|c|c|c|c|c|c|c|}
\hline & AFP & $\mathrm{n}$ & Median & P25-P75 & Mean Rank & Z & $P$ \\
\hline \multirow[t]{2}{*}{ Hcy $(\mu \mathrm{g} / \mathrm{L})$} & - & 88 & 15.10 & $12.10-20.85$ & 87.94 & -0.764 & 0.445 \\
\hline & + & 93 & 15.60 & $12.40-21.80$ & 93.89 & & \\
\hline \multirow[t]{2}{*}{$S F(\mu g / L)$} & - & 163 & 556.10 & $261.00-1061.71$ & 210.37 & -0.217 & 0.828 \\
\hline & + & 260 & 570.65 & $270.42-1188.63$ & 213.02 & & \\
\hline \multirow[t]{2}{*}{ ALT (U/L) } & - & 348 & 32.00 & $20.00-53.00$ & 451.98 & -5.344 & 0.000 \\
\hline & + & 696 & 42.00 & $27.00-67.00$ & 557.76 & & \\
\hline \multirow[t]{2}{*}{ V-GT (U/L) } & - & 348 & 78.00 & $40.25-163.00$ & 427.60 & -7.191 & 0.000 \\
\hline & + & 696 & 142.00 & $67.25-268.75$ & 569.95 & & \\
\hline \multirow[t]{2}{*}{$\mathrm{Y}-\mathrm{GT} / \mathrm{ALT}$} & - & 348 & 1.32 & $0.54-3.11$ & 558.34 & -2.716 & 0.007 \\
\hline & + & 696 & 0.94 & $0.29-3.31$ & 504.58 & & \\
\hline \multirow[t]{2}{*}{ AST (U/L) } & - & 349 & 41.00 & $27.00-63.00$ & 404.51 & -9.014 & 0.000 \\
\hline & + & 697 & 64.00 & $39.50-124.50$ & 583.08 & & \\
\hline \multirow[t]{2}{*}{ AFU (U/L) } & - & 331 & 27.00 & $22.10-34.00$ & 373.54 & -9.883 & 0.000 \\
\hline & + & 673 & 36.30 & $27.10-50.25$ & 565.92 & & \\
\hline \multirow[t]{2}{*}{$\mathrm{DBIL}(\mu \mathrm{mol} / \mathrm{L})$} & - & 347 & 4.90 & $3.40-9.90$ & 470.33 & -3.911 & 0.000 \\
\hline & + & 696 & 6.45 & $4.00-13.98$ & 547.76 & & \\
\hline \multirow[t]{2}{*}{ IBIL ( $\mu \mathrm{mol} / \mathrm{L})$} & - & 347 & 11.40 & $7.60-17.50$ & 492.41 & -2.240 & 0.025 \\
\hline & + & 696 & 12.40 & $8.30-20.68$ & 536.75 & & \\
\hline \multirow[t]{2}{*}{ TP (g/L) } & - & 348 & 67.05 & $62.30-72.20$ & 503.26 & -1.385 & 0.166 \\
\hline & + & 694 & 67.30 & $62.70-72.93$ & 530.65 & & \\
\hline \multirow[t]{2}{*}{ ALB (g/L) } & - & 348 & 35.90 & $30.93-40.60$ & 535.19 & -0.961 & 0.336 \\
\hline & + & 696 & 35.10 & $30.80-39.90$ & 516.16 & & \\
\hline \multirow[t]{2}{*}{ PT (sec) } & - & 347 & 14.20 & $13.30-15.30$ & 496.19 & -1.812 & 0.070 \\
\hline & + & 692 & 14.40 & $13.60-15.40$ & 531.94 & & \\
\hline \multirow[t]{2}{*}{ INR } & - & 247 & 1.13 & $1.05-1.23$ & 399.52 & -0.678 & 0.498 \\
\hline & + & 568 & 1.14 & $1.06-1.24$ & 411.69 & & \\
\hline \multirow[t]{2}{*}{ Fibrinogen } & & 246 & 3.11 & $2.52-4.30$ & 374.54 & -2.668 & 0.008 \\
\hline & & 569 & 3.48 & $2.67-4.53$ & 422.46 & & \\
\hline
\end{tabular}




$\begin{array}{lllllll}\text { D-Dimer } & 228 & 0.89 & 0.42-2.41 & 338.29 & -3.716 & 0.000 \\ & 539 & 1.34 & 0.66-2.92 & 403.34 & & \end{array}$

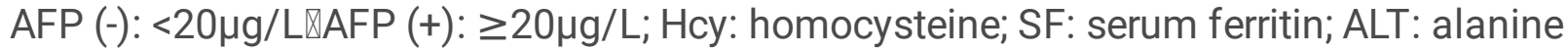
aminotransferase; g-GT: g-glutamyl transpeptidase; AST: Aspartate aminotransferase; AFU: alpha-Lfucosidase; DBIL: direct bilirubin; IBIL: indirect bilirubin; TP: total protein; ALB: albumin; PT: prothrombin time; INR: international normalized ratio

Table 5 Association between serum AFP levels and hematology parameters (Mann-Whitney)

\begin{tabular}{llllllll} 
& AFP & $\mathrm{n}$ & Median & P25-P75 & Mean Rank & $\mathrm{Z}$ & $P$ \\
\hline WBC & - & 349 & 6.04 & $4.53-7.89$ & 487.43 & -2.767 & 0.006 \\
\hline & + & 698 & 6.49 & $5.00-8.39$ & 542.28 & & \\
\hline Neu & - & 349 & 3.62 & $2.55-5.52$ & 478.07 & -3.475 & 0.001 \\
\hline & + & 698 & 4.19 & $3.02-6.00$ & 546.97 & & \\
\hline Neu\% & - & 349 & 64.00 & $55.85-73.30$ & 479.40 & -3.375 & 0.001 \\
\hline & + & 698 & 67.00 & $59.00-74.40$ & 546.30 & & \\
\hline Lym & - & 349 & 1.40 & $0.98-1.88$ & 530.18 & -0.468 & 0.640 \\
\hline & + & 698 & 1.37 & $1.00-1.86$ & 520.91 & & \\
\hline Lym\% & - & 349 & 25.50 & $15.80-33.00$ & 566.38 & -3.207 & 0.001 \\
\hline & + & 698 & 22.00 & $15.00-29.15$ & 502.81 & & \\
\hline NLR & - & 349 & 2.45 & $1.70-4.68$ & 480.47 & -3.293 & 0.001 \\
\hline & + & 698 & 3.05 & $2.04-4.93$ & 545.76 & & \\
\hline Mon & - & 349 & 0.47 & $0.33-0.65$ & 496.12 & -2.110 & 0.035 \\
\hline & + & 698 & 0.50 & $0.37-0.69$ & 537.94 & & \\
\hline Mon\% & - & 349 & 8.00 & $6.00-10.00$ & 521.48 & -0.191 & 0.849 \\
\hline & + & 698 & 8.00 & $6.10-10.00$ & 525.26 & & \\
\hline PLT & - & 249 & 168 & $126-227$ & 379.62 & -2.502 & 0.012 \\
\hline & + & 572 & 192 & $127-260$ & 424.66 & & \\
\hline
\end{tabular}

AFP (-): $<20 \mu \mathrm{g} / \mathrm{L} \mathbb{A F P}(+): \geq 20 \mu \mathrm{g} / \mathrm{L} ;$ WBC: white blood cell count; Neu: neutrophil count; Neu\%: percentage of neutrophils; Lym: lymphocyte count; Lym\%: percentage of lymphocytes; NLR: neutrophil to lymphocyte ratio; Mon: monocyte count; Mon\%: percentage of monocytes; PLT: platelet count. 
Figures

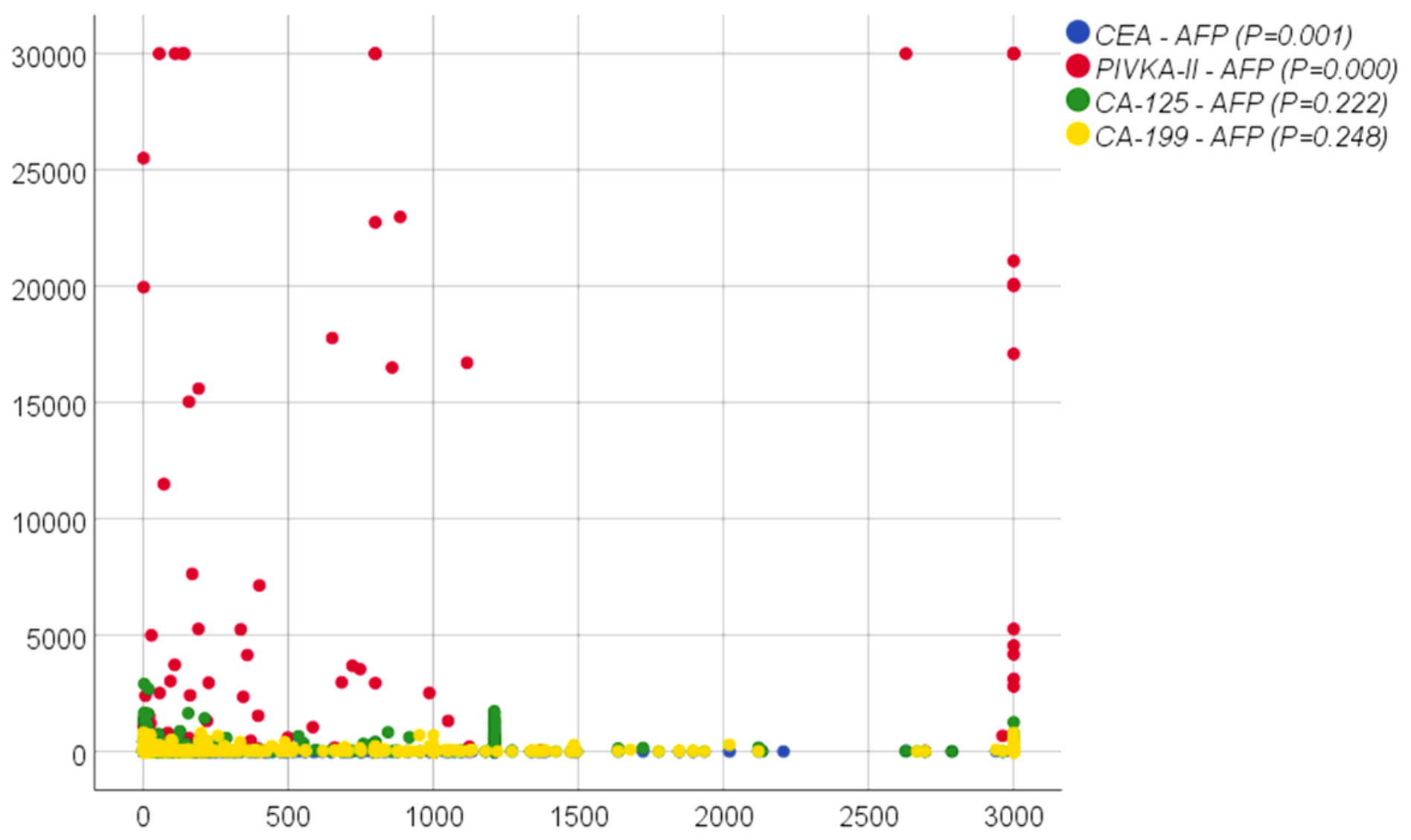

Figure 1

The overlay scatter of serum AFP levels with other tumor markers (PIVKA-II, CEA, CA-125, and CA-199) Figure 1 shows the association between serum AFP levels and PIVKA-II, CEA, CA-125, and CA-199 in HCC patients using the overlay scatter plot, a $\mathrm{p}$ value is displayed.

\section{Supplementary Files}

This is a list of supplementary files associated with this preprint. Click to download.

- ChietalSupplFigures.docx

- ChietalSupplTables.docx 